\title{
Managing experience co-creation practices: Direct and indirect inducement in pop-up food tourism events
}

\author{
Peter Lugosi* 1 \\ Oxford Brookes University \\ Email: plugosi@brookes.ac.uk \\ Richard N.S. Robinson \\ The University of Queensland \\ Gabby Walters \\ The University of Queensland \\ Sarah Donaghy \\ The University of Queensland \\ *Corresponding author
}

Published as: Lugosi, P., Robinson, R.N.S., Walters, G., \& Donaghy, S. (2020)

Managing experience co-creation practices: Direct and indirect inducement in pop-up food tourism events. Tourism Management Perspectives, 35, 100702, DOI:

10.1016/j.tmp.2020.100702. Please consult the final published version if citing.

\begin{abstract}
Consumers performing the role of value-creators in experience co-creation introduces idiosyncrasies that challenge experiential consistency. Taking 'pop-up' dining events as its empirical focus, and drawing on semi-structured interviews with participants, this study examines how organisations and consumers interact to negotiate ambiguity, variability and consistency. The paper questions how organisers try to prescribe normative rules governing events. It considers how consumers invest in preparing for events, and engage in socialised performances to create unique experiences. The data are also used to show how peer surveillance shapes consumer expectations, behaviours and interpretations. Consequently, this study contributes to knowledge on the practical management of co-creation by conceptualising different pathways through which organisations and consumers attempt to orchestrate behaviours. Moreover, in theorising from the data, this paper distinguishes between direct and indirect modes of inducement used to achieve experiential outcomes, identifying how 'value-signalling' practices engage event stakeholders and shape their co-creation.
\end{abstract}

Keywords: Co-creation; Consumer socialisation; Food and drink tourism; Habitus; Interpellation; Memorable experiences; Social practices; Value creation

\footnotetext{
1 This study was partially funded by Oxford Brookes University and the University of Queensland as part of an International Collaborative Research Funding Scheme. We wish to acknowledge the work of Ms Toya Bezzola who contributed to this project as a funded research assistant.
} 


\section{Introduction}

Proponents of service and marketing management approaches frequently conceptualise consumption experiences as a series of steps with various elements that can be managed to ensure optimal outcomes for providers and customers (Berry, Wall, \& Carbone, 2006; Bitner, Ostrom, \& Morgan, 2008; Ponsignon, Durrieu, \& BouzdineChameeva, 2017; Scott, Gao, \& Ma, 2017; Zomerdijk, \& Voss, 2010). However, researchers in tourism and related fields have acknowledged that consumption experiences involve elements that are difficult to anticipate or direct because they operate in spatial and temporal spheres that cannot be entirely monitored or controlled by service organisations (Grönroos \& Voima, 2013; Marques \& Borba, 2017; Torres, Lugosi, Orlowski, \& Ronzoni, 2018). Arguably, in tourism, service or other leisure contexts where organisations and consumers interact, operators may attempt to direct or channel consumer perceptions and behaviour. However, the cognitive or affective value of experiences are actually created or realised by consumers (Grönroos \& Voima, 2013; Helkkula, Kelleher, \& Pihlström, 2012; Lugosi, 2014; Prebensen, Chen, \& Uysal, 2018).

The problems of ambiguity and the absence of controllability are multiplied in temporary 'pop-up' tourism and hospitality events. Such events are: a) irregular, shifting form according to the theme, market context and the venues, which were not necessarily built to host them; and b) mobile, insofar as they do not always use the same venue (cf. Berridge, 2007; Bowdin, Allen, O'Toole, Harris, \& McDonnell, 2012; Tum, Norton \& Wright, 2006). Such mobility and irregularity create a number of challenges for tourism, hospitality and event management and for experience co-creation more widely. Firstly, from an operations management and marketing perspective, the use of new venues, which may not have been designed for events, presents ambiguities and thus risks regarding the experiential propositions that can be conveyed, the expectations that can be built and the delivery of the experience. Secondly, from the consumer's perspective, the potential to visit an unusual or unknown spatial location introduces unpredictability, which may drive positive anticipation of novelty but also evoke risks stemming from an inability to plan and set appropriate expectations for the consumption experience.

Pop-up dining and food tourism experiences embody the challenges highlighted above regarding the difficulties of predicting, monitoring or even orchestrating consumer co-creation, which are amplified by the hosting of events in irregular venues. This paper uses a global 'pop-up' food tourism phenomenon as the empirical context to conceptualise the processes through which consumer practices and resources are mobilised to create experiences in event settings that are characterised by mobility and irregularity. Moreover, it distinguishes between direct and indirect processes, or pathways, through which organisations may try to instigate and subsequently orchestrate the co-creation of events.

This paper contributes to knowledge in several ways. Firstly, Jaakkola, Helkkula, and Aarikka-Stenroos (2015) noted that there is a need to better account for the spatial and temporal dimensions of value-creation. Our data enable us to demonstrate how value-creation takes place across time and space, and in doing so we extend existing work on 'structured experiences' (Duerden, Ward \& Freeman, 2015) by examining how diverse material and embodied practices are mobilised in the structuring or orchestration of event experiences. Secondly, Duerden et al., (2018) have criticised the co-creation literature for being atheoretical. Drawing on Bourdieu's (1977[1972], 1986) work on habitus and forms of capital, and complementary socio-political studies of class and culture (Althusser, 2001[1971]; Bakhtin, 1986[1953]; Barthes, 1993[1957]; Vološinov, 
1986[1929]), we theorise how individuals are engaged through culturally encoded signals, and mobilise multiple forms of capital, using material and embodied performances to perpetuate group habitus in experience co-creation.

Thirdly, as noted above, the literature on service and experience co-creation has grappled with the manageability of consumer experiences, with some arguing that value creation is consumer-driven, and importantly, is enacted in spaces and times outside of the organisation's influence (Grönroos \& Voima, 2013). More recently, Ellis, Freeman, Jamal and Jiang also stressed that there is compelling need to develop "propositions or strategies for managing or facilitating co-creation" (2019, p.113). From our theorisation of the data we present a conceptual model that accounts for how the 'provider' may try to shape consumer practices, including in spaces and times that are outside of their direct influence.

Fourthly, in response to Laing's (2018) observations regarding the limited theoretical foundations of event and event tourism research, our conceptualisation helps to develop a more sophisticated theorisation of these phenomena, including their management. Finally, the study also responds to recent calls for empirical studies examining links between gastronomic tourism and tourist behaviours, with specific focus on quests for unique tourism experiences (cf. Özdemir \& Seyitoğlu, 2017). The paper thus contributes broadly to the conceptualisation and management of experience co-creation in tourism and analogous fields, and more specifically to how co-creation may be managed in unusual and irregular event and tourism contexts.

\section{Literature review}

\subsection{Event co-creation as embodied performance}

Social events are fundamentally affective, co-created and embodied experiences (cf. Crowther \& Donlan, 2011; Morgan, 2008; Werner, Griese, \& Faatz, 2019; Ziakas $\&$ Boukas, 2013). These features are even more acutely important in food-related events. The body is the essential consumption site where food and drink are ingested to satiate social, symbolic as well as physical needs to commemorate, celebrate, enjoy or even escape. Moreover, such events are brought to life, or co-performed, through a series of embodied rituals and practices (cf. Plester, 2015; Lugosi, 2014; Warde, 2016).

The embodied co-creation of events requires collective action by a range of actors with shared frames of reference regarding common goals, capacities and practices through which these could be achieved (Lundberg \& Ziakas, 2018; Sterchele, 2020; Ziakas \& Costa, 2012). Bourdieu's (1977; 1984[1979]) work on habitus and related approaches to ideology and class relations (Althusser, 2001; Bakhtin, 1986; Barthes, 1993; Bourdieu, 1986; Vološinov, 1986) provide a useful framework for conceptualising such shared frames of references and their reproduction. Habitus refers to dispositions and capacities that people acquire and refine through their socialisation into a (class) group (Bourdieu, 1977, 1984). Habitus is an internalised, sensemaking practice; it is embodied, becoming part of routinized actions, and performed, enabling individuals to assert their belonging to a group. Moreover, perpetuating these dispositions continues to objectify and thus reproduce the group's norms and values over space and time.

The notion of habitus has been criticised for being overly deterministic and reducing the potential for individual agency (Adams, 2006). Nevertheless, it is important to acknowledge the normative capacities of habitus to encode values and norms into social practices, and thus setting the terms of engagement for group 
members. Social position and group status is consequently shaped and evaluated in relation to the ongoing embodied performance of habitus.

The expressive, performed nature of habitus ties its perpetuation to mutual surveillance and judgement regarding what is considered acceptable or 'deviant' in the context of group norms (Adler \& Adler, 2015). Just as skilful conformance to group habitus can be rewarded, deviation from or subversion of group practices can incur sanctions, including status devaluation and exclusion. Such deviance may be deliberate or stem from the absence of capacities and resources, for example knowledge of norms and rituals. Ascribing 'deviant' labels to embodied practices and to those performing them can thus 'be seen as attempts to exercise power over others in a particular time and place' (Lugosi, 2019, p.83).

Importantly, habitus is constructed and perpetuated through the mobilisation of economic and symbolic forms of capital (Bourdieu, 1977, 1986). Beyond financial capacities (i.e. economic capital), social capital refers to the strength of social networks, which enable members to access and deploy various resources (cf. Putnam, 2000). Cultural capital refers to knowledge, skills and experiences, which may emerge in 'embodied' forms i.e. 'dispositions of minds and body', or 'objectified' ones 'in the form of cultural goods' (Bourdieu, 1986, p.243). Different forms of capital become embedded in performing habitus, and the conformance to or deviation from group norms and practices are tied to individuals' ability to access and mobilise multiple forms of capital simultaneously.

Habitus and forms of capital provide a useful sensitizing framework for understanding how and why food and drink related events are co-created. Engaging in the production and consumption of event experiences can be viewed as particular 'cultural utterances' - expressions of encoded class and identity position, referencing ideologies regarding what is valued, 'proper' and desirable (Bakhtin, 1986). As Vološinov (1986, p.72) argued, such expressions or utterances are constructed in relation to existing webs of communication and systems of meaning:

\begin{abstract}
Any utterance [...] makes response to something and is calculated to be responded to in turn. It is but one link in a continuous chain of speech performances. Each monument carries on the work of its predecessors, polemicizing with them, expecting active, responsive understanding, and anticipating such understanding in return.
\end{abstract}

The co-creation of events can be seen as the collective embodied performance of habitus - encoded values and value systems in which they are positioned. Moreover, embodied performances within event contexts reflect the dispositions and capacities determining inclusion into the group with whom the event is experienced. Participating in event co-creation thus signals awareness and appreciation of the norms, values and principles associated with the event's experiential propositions, which relies on receiving and decoding culture-specific messages.

Althusser (2001[1971]) provides a useful perspective for understanding how the signalling of values and principles may draw individuals into embodied performances in event co-creation. Althusser (2001) proposed the notion of 'interpellation', or hailing, to conceptualise the practices through which individuals become the subjects of political and ideological discourses. This requires subjects to acknowledge that they are being summoned i.e. called to recognise communication signals, and have the capacities to 
interpret the meaningfulness of the signs, both of which are tied to particular (group or class-based) dispositions and capacities i.e. habitus. More importantly, individuals identify with the values and principles being communicated, insofar as they have a shared habitus, and event experiences reflect common goals, for example belonging and status. Finally, they have the resources in the forms of economic, social and cultural capital to invest in co-creating events. The challenge for the current study is to examine how and why such dispositions, capacities and embodied performances emerge within the co-creation of (food-related) consumer events and event experiences. More specifically how they are mobilised purposefully to create particular forms of consumption events, resulting in desired experiences.

\title{
2.2 Co-created consumer events and experiences
}

Consumer experiences are created through interactions of human and nonhuman elements (Hoffman \& Turley, 2002; Lugosi, 2014; Marques \& Borba, 2017; Zomerdijk \& Voss, 2010) that take place across time and space. Event and venue organisers may be able to assert direct control over some of these elements and their interactions within the servicescape, where organisations and their customers come into direct contact. However, as Ellis et al. (2019, p.110) stressed, guest or participants' behaviour or their subjective experiences are not fully controllable.

Lugosi (2014, p.173) proposed that the creation of event experiences within venues could be conceived as 'inducement - a process through which conceptions of identity, (sub)cultural values and beliefs, and expressive behaviours were brought together in the recreation of experiential space.' More specifically, Lugosi argued that:

\begin{abstract}
Inducement involves the continual mobilisation of labour and capital, the manipulation of the servicescape, juxtapositioning of objects and sounds, representational acts and embodied performances of selves that perpetuate experiential possibilities. In other words, the combination of these elements makes it possible, though does not guarantee, that specific hedonic experiences are accessible. It is important to stress that inducement should not be thought of as a purely managerial exercise; rather it is a process where the commercial operators construct 'propositions' ..., partly through the 'indexing' and 'dragging' of cultural references ..., and the creation of 'clues' for the consumer ..., which are received, interpreted, resisted and realised by consumers (2014, p.173).
\end{abstract}

Inducement thus relies on a combination of spatial, material, (embodied) performative and representational practices (ibid.). Such practices index and utilise group habitus, alongside consumers' economic and symbolic capital to create and signal experiential propositions, interpellate constituent actors and attempt to mobilise them to co-create event experiences.

Insofar as events have a distinct spatial focus where organisers and customers interact, intensively, in discrete, bounded contexts during relatively short periods (Binkhorst \& Den Dekker, 2009), the notion of inducement is useful for understanding event co-creation practices primarily within operational contexts. However, researchers acknowledge that experiences are spatially and temporally distributed: interactions between consumers and organisations begin before consumers enter venues, and continue long after they depart (Duerden et al., 2015; Grönroos \& Voima, 2013; Torres 
et al., 2018). Moreover, consumption experiences involve various psychological and affective processes (e.g. imagination, fantasy, desire), practical behaviours (consumer learning, decision making, pre-visit preparation), and post-event actions (e.g. selfrepresentations through social media for social and ego reasons, evaluations of value, word-of-mouth and repurchasing). These practices operate outside of 'governable' (event, tourism, leisure or hospitality) organisational spaces (Grönroos \& Voima, 2013). Researchers have consequently called on colleagues to deepen our understandings of consumer practices in the co-creation of experiences in and across space and time, more broadly (cf. Lugosi, 2014; Torres et al., 2018) and in event (Holst-Kjaer, 2011) and tourism contexts specifically (Prebensen \& Xie, 2017).

Within pop-up experiences, challenges regarding transparency and governability of consumer practices are compounded by the mobility and irregularity characterising the events. The mapping of consumer journeys, the definition of participants' roles and the identification of touchpoints, when organisations come into contact with their customers, is limited by the changing form of the events and their contexts. This can refer to their geographical distribution in spaces such as cityscapes (cf. Bell, 2007), as well as the micro-level materiality of venues: for example layout, access to basic infrastructural requirements such as electrical supply, water, temperature control, toilet facilities, access for people with mobility requirements etc. Creating popup events also raises logistical challenges, for instance transporting equipment, goods and service staff, and access for customers (Berridge, 2007; Bowdin, Allen, O'Toole, Harris, \& McDonnell, 2012; Tum, Norton \& Wright, 2006). In combination, the spatial and temporal distribution of consumption experiences, and the practical challenges of pop-up events, make the application of experience design principles more complicated. This further highlights the need to broaden existing conceptions of co-creation practices, especially within pop-up events. There is a particular need to question what consumer practices are involved in co-creating these experiences, particularly those beyond the 'joint sphere' (Grönroos \& Voima, 2013) of the servicescape where customers and providers come into direct contact. Consequently, it is necessary to develop an understanding of how organisations responsible for the execution of pop-up events, which are also characterised by mobility and irregularity, can manage co-creation practices.

\subsection{Pop-up experiences and consumption}

Pop-up businesses and pop-up venues as operational models of experiential consumption in tourism, hospitality, leisure and retail have grown considerably in recent years (Aaltojärvi, Kontukoski, \& Hopia, 2018; Ferreri, 2015; Harris, 2015, 2017; Jones, Comfort, \& Hillier, 2017; Obrador Pons, 2020; Schaller \& Guinand, 2018). For the purposes of the current discussion, we define pop-ups as the temporary occupation of spaces for value-creating practices. For organisations, value may be in the form of economic capital or the refinement of brand value (cf. Klein, Falk, Esch, \& Gloukhovtsev, 2016). For consumers, especially in an event context, value can take more immediate experiential, affective forms, for example creating feelings of joy or excitement (Morgan, 2008; Torres et al., 2018). However, value may emerge in sustained forms, over time, for example as social capital insofar as consumption practices contribute to the building of mutuality and interdependency among communities or networks of consumers (Batat, Peter, Moscato, Castro, Chan, Chugani, \& Muldrow, 2018; Cannas, Argiolas \& Cabiddu, 2019). Importantly, the spaces 
occupied by pop-ups may not have been designed or originally used for the purposes envisioned by those managing or operating the pop-up. Pop-ups may thus be part of broader creative and disruptive activities that seek to subvert spaces, particularly in urban settings (cf. Lugosi, Bell, \& Lugosi, 2010; Harris, 2015, 2017; Schaller \& Guinand, 2018).

Much of the business and management research on pop-ups has focused on the retail sector (cf. Hietanen, Mattila, Schouten, Sihvonen, \& Toyoki, 2016; De Lassus, \& Freire, 2014; Kim, Fiore, Niehm, \& Jeong, 2010; Klein et al., 2016). Yet pop-up food events have grown significantly in popularity in recent years (Hoffman, 2015). Apart from the limited acknowledgement of their presence in urban cultures (cf. Lim, 2015; McLaren \& Agyeman, 2015), specifically pop-up restaurants (cf. Aaltojärvi, Kontukoski, \& Hopia, 2018; Jones et al., 2017; Taylor, DiPietro \& So, 2018), there have been no attempts to examine larger scale food and dining-related pop-up events as spaces and practices of value creation. Consequently, in addition to contributing to a broader conceptualisation of experience co-creation in mobile, irregular settings, the current study also contributes to our understanding of pop-ups as experiential products and operations in a tourism and events setting.

\section{Study methods}

\subsection{Research context: 'White Dinner' pop-up events}

The empirical contexts for our analysis of pop-up event experience co-creation are so-called 'White Dinners'. The 'Diner en Blanc' concept (dinerenblanc.com) is a themed pop-up event, during which guests are expected to wear solely white and to bring along their own table, chairs and gourmet food. The dinners take place in novel and often visually striking venues, for example in parks or other urban spaces that are not originally or exclusively used for foodservice. More importantly, the formal or 'official' Diner en Blanc concept has emerged as a globally-branded genre of events and tourism attractions, where subscribed members of the network are led to an undisclosed dining location, adding to the novelty and exclusiveness of the event experience. However, 'White' events have also emerged in other destinations, which emulate some aspects of the 'Diner en Blanc' model.

The White events were purposefully selected as the empirical focus for several reasons. Firstly, given the limited research into pop-up experiences in general, and foodspecific events in particular, these acted as useful 'critical cases' (Patton, 2014) because they were examples of both such phenomena. Secondly, White events had a historical dimension, alongside elements of novelty and ambiguity insofar as they were held in new, unknown locations, which were not necessarily designed for food-specific events. Studying White events thus allowed us to examine how issues around continuity, for example, regarding the values, practices and audiences they engaged, coexisted with those of discontinuity stemming from their shifting location. Finally, a key choice of specific White events and their clientele was access. This was a closed consumption community, and in the initial stages, one of the authors attended a White event, using her experiences and connections to access participants. A research assistant also provided access to a second group of participants in a different national context.

White events were examined in two different locations: the first in a metropolitan Eastern-Australia destination; and a second, in a central Swiss city, which reproduced many but not all of the Diner en Blanc events' characteristics. The study's objective was not to conduct a comparative analysis of Australian and Swiss event 
experiences. Rather, the intention was to explore a multiplicity of perspectives and experiences, which was facilitated by recruiting participants across the two countries.

At the time of the research, the Australian dinner was embedded in the city's calendar, and some of the participants were repeat attendees. As there were limited places available, attendees registered online, usually with friendship groups, after which they received detailed instructions on the event rules. Attendees fully self-catered, from food and beverages, crockery and glassware, table decor and accoutrements, even tables and chairs. Attendees were instructed on the strict protocols: everything must be white, from clothing, tableware and ideally the food. The location was concealed, such that on the evening of the event attendees congregated at collection points, with all their paraphernalia, and were bussed to the urban event venue, which, apart from lighting, music and some staging for dancing, awaited adornment by the event attendees.

The Swiss event adhered to similar processes and practices, with the notable exception that, unlike the Australian event, the town square location was disclosed to participants, and tables were provided. Moreover, the Swiss attendees were able to prepurchase event merchandise, notably the souvenir 'White Dinner chair', and the organisers augmented the event with entertainers. The Swiss 'White Dinner' was the inaugural iteration and for many of the participants this was their first pop-up experience. Both events evolved organically but there were some shared choreographed moments, for example everyone waving napkins to signal the start of the meal.

\subsection{Study approach and data collection}

Scant attention has been paid to pop-up event experiences within tourism and hospitality contexts. Therefore, an exploratory, inductive approach in the constructivist tradition was adopted (Lincoln \& Guba, 2013). Semi-structured interviews were conducted to capture the perspectives of a diverse sample of consumers with direct experiences of White Dinner events. Given the exclusive nature of the 'White' experience, the study adopted a mixture of purposive and snowball approaches to sampling, which were used to recruit 15 participants in Australia and a further 15 in Switzerland (See Table 1 for an overview of the sample). Sample symmetry was coincidental and not an objective. The essential inclusion criterion was that people had to have experienced a White event. Token incentives were offered to participants in both contexts. Similar to other studies, interviews were typically conducted in public, neutral spaces, which sought to make respondents comfortable and to reduce interviewerinterviewee power differentials (cf. Lugosi, Robinson, Golubovskaya, Foley, \& Harwell, 2016). 
Table 1: Participant Profiles

\begin{tabular}{|l|l|l|l|l|l|}
\hline \multicolumn{5}{|l|}{ Switzerland } & \multicolumn{5}{l|}{ Australia } \\
\hline Name & Gender & Age & Name & Gender & Age \\
\hline Frolinda & F & $55-64$ & Holly & F & $18-24$ \\
\hline Gian & M & $65-74$ & Jessica & F & $35-44$ \\
\hline Zena & F & $65-74$ & Michael & M & $45-54$ \\
\hline Chiara & F & $45-54$ & Chelsea & F & $18-24$ \\
\hline Hans & M & $55-64$ & Kate & F & $18-24$ \\
\hline Jan & M & $75+$ & Josh & M & $18-24$ \\
\hline Seraphine & F & $75+$ & Cherie & F & $18-24$ \\
\hline Eric & M & $25-34$ & Emily & F & $25-34$ \\
\hline Sonia & F & $18-24$ & Rachel & F & $25-34$ \\
\hline Jurg & M & $65-74$ & Jacob & M & $45-54$ \\
\hline Romina & F & $45-54$ & Sophie & F & $18-24$ \\
\hline Julia & F & $18-24$ & Tracey & F & $35-44$ \\
\hline Margrit & F & $65-74$ & Stephanie & F & $25-34$ \\
\hline Cristina & F & $45-54$ & Hannah & F & $45-54$ \\
\hline Alex & M & $55-64$ & Alarna & F & $35-44$ \\
\hline
\end{tabular}

The interview protocols were based on 10 core question and subsequent followup probes (see Appendix 1. for details). They were designed to explore five domains: 1. how and why event participation (and preparation) linked to identities (as expressions of status and belonging); 2 . the importance of materiality and culture as manifested at the event; 3 . descriptions of the experiencescape; 4 . practices reflecting investment (in time, money and other resources); and 5. motivations to (re)attend. All the interviews were digitally recorded and transcribed. The Swiss interviews, conducted in SwissGerman, were transcribed and translated by a native German speaker with fluent English, who had studied and worked in a Swiss-German canton for three years, and cross-checked by the Swiss-German interviewer.

\subsection{Data analysis}

Following Lincoln and Guba (2013), the coding, data reduction and ordering was managed in several interactive cycles to ensure the trustworthiness of the findings and conclusions. However, the research team was keen to avoid relying on simplistic 'criteriology' (Schwandt, 1996) and reductive 'methodological proceduralism' (Hammersley, 2010), for example measures of inter-rater reliability. Nevertheless, the analysis sought to assure 'credibility' through 'researcher triangulation' (Denzin, 2009), which involved three researchers coding the data independently.

In the initial coding and sorting cycle, an inductive thematic approach was applied, regardless of the constructs scaffolding the interview protocol (see Braun \& 
Clarke, 2006). In an iterative process, involving several extended discussions between the authors, the data were reordered in subsequent analysis cycles. The data ordering and display were increasingly driven by explicitly stated codes, for example distinguishing between organisationally prescribed norms and practices emerging in participants' narratives, which interpreted, enacted and occasionally transformed those norms.

Through discussions and attempts to reorder the data, five pervading themes were identified, under which the sub-codes were organised and synthesised: normative discourses; temporality; 'backstage' investedness; 'frontstage' performances and serendipity. These five themes were reordered into three meta-themes - setting experiential rules, consumer enacted investedness, and socialised performances, with some peripheral issues such as serendipitous incidents set aside to provide a clearer focus on substantial alternatives. These three themes formed the basis of a framework for conceptualising individual and interacting organisational and consumer practices through which the pop-up events were co-created. These helped to differentiate between prescribed and ritualised elements in the events, the evolution of the events and the 'place-myths' (Shields, 1991) around them, consumers' various embodied performances, and the peripheral, 'ungovernable' elements that influenced the events.

\section{Findings}

\subsection{Setting experiential 'rules'}

Within the context of 'White' events, the organisation sought to (re)produce and communicate a series of values and principles, reflecting the aesthetic dimensions of the experience and the importance of performing coordinated practices, thus conforming to group norms. However, whereas values may be abstract and sublime, making them difficult to prescribe, the organisers codified certain patterns of behaviour as rules that governed the core elements of the proposed experience, which arguably acted as proxies of values entangled in the fundamental experiential proposition. In this context the terms of engagement needed to be clearly understood by participants and enforced by the management team to ensure an element of authenticity and experiential consistency. Organisers communicated explicitly the rules and regulations to attendees to achieve the events' distinctive atmosphere. The desired themes and 'feelings' the organisers sought to mobilise were communicated via their direct marketing, with detailed instructions being given to members and the physical assets used to embellish the location.

However, it is important to appreciate that for normative discourses to function, they require a receptive audience, who can decode the signals, or 'cultural utterances' and translate them into practice. In the case of the White events, these explicit rules were embraced by attendees and the data was indicative of a strong willingness to follow them as participants recognised the importance of performing the shared habitus to ensure the success of the envisaged experience.

I have no problem with any of the rules, I think the reason why it is so popular and so well structured is because of those rules... you know everyone is wearing white, white lined, white table it's part of the experience... the rules are there for a reason. (Jessica) 
They [the rules] were clear it's not like there was too many of them and it revolves around maintaining the integrity of the night which is important because you are all there for the same reason. (Jacob)

Yeah, [the rules are important] otherwise people are going to be thinking they can bring anything they want, and when you look at this event there is a clear idea that internationally, not just in [the city], that you need to have these things to make this event possible. (Sophie)

Such observations indicate that attendees understood that the rules and instructions made an event successful - in other words they internalised them as they informed their embodied performances. The rules also provided those who played the role of group leader with points of reference that enabled them to enforce these rules when socialising others into conforming to experiential norms. In short, this helped to perpetuate the group habitus.

To make them functional, rules have to be understood, in spirit and in practice, which required a number of transmission practices. Some of the rules and expectations were clearly stated as part of the textual instructions provided to participants. Others were communicated through preparation practices, as organisations mobilised a range of artefacts to enact organisational discourses. For example, in the Swiss event, the souvenir themed chairs were purchased alongside the vast array of tableware, accoutrements and even consumables. The expectation to purchase these articulated active processes by the organisers to reproduce and normalise place-myths surrounding the 'White Dinner' experience (Shields, 1991).

Explicit transmission of normative rules attempted to mitigate risks and uncertainties associated with the event. Importantly, participants' reflections on the rules pointed to further, normative practices of internalisation and peer socialisation among consumers through which such rules were perpetuated. For example, Chiara noted: "it would be unfair towards the organiser and the city to not follow the dress code". In short, participants were (made) acutely aware of the risks for the event experience, and the event stakeholders, including themselves, posed by deviation from or subversion of codified values. The next section thus explores consumers' roles in enacting and thereby transmitting key aspects of experience co-creation in greater detail.

\subsection{Enacting 'investedness'}

Active participation was exhibited by event participants via their temporal, behavioural, psychological, social and financial investment, including their explicit acknowledgement of the importance of their efforts to the successful co-creation of the event. The amount of time invested in preparations varied greatly between first timers and repeat attendees, with initiates spending from two weeks to two to three months preparing, and some repeat attendees starting their preparations a year before the event.

It's like anything, the more you invest in an experience the more you get out of it. [...] Not going to say the word posh but the friends and social group that I am in would regard [a White event] as a night to dress up, because you are dressing up for other people as well as just for everyone to understand that it is a night to invest in. (Jacob) 
Others stressed their reinterpretation or stylisation of the event theme to suit their group's unique self-expression. For example, Sophie stated: "our theme was chantilly shabby chic... if you don't theme it and put in the energy to it you are going to feel disappointed". These reflect the internalisation of the values that were essential to the experience, and the self-awareness that their performative co-creation was essential to enacting or reifying those values.

Importantly, investment was tied to a sense of mutual surveillance, where participants knew they would be subjected to the judgemental gaze of their fellow participants; in the same way that they would (be expected to) judge others. Mutual and self-surveillance thus drove self-reflection, which foregrounded personal appearance and the expectation to 'look the part'; in essence, to fit in with their peers. For example: "Probably the only thing I worry about in advance is what I am going to wear." (Tracey); or "Yeah, because I felt like if they didn't let me in or make a comment on my shoes I am not going to feel welcome in this [White event] community." (Kate).

Such investment involved financial commitment reflecting the role of economic capital in asserting belonging. Participants were also expected to invest in cultural capital, for example through the props required to perform the codified values embedded in the event practices. This further highlights the role of peer socialisation into the group habitus, as consumers' actions shaped the terms of engagement with the event for their friends and family:

If you going to do an event like this do it properly you know? So the first year my husband went out and bought a full white suit and we took his brother for his $18^{\text {th }}$ so we gave him a full white suit for his birthday too. The outfit is very important because it is part of it, it is part of the whole thing. (Stephanie)

Spending varied among participants, but it was evident that the cultural and financial investment was driven by a sense of obligation among attendees to spend what was necessary to ensure that the White experiential proposition was enacted. Fashion, décor and table arrangements followed by food were commonly cited as the order of priority with the largest investment generally being clothing:

Well it is marketed as a glamour affair; it's like anything, you don't want someone to turn up to a wedding in board shorts for the same reason... you want to maintain a certain level of decorum. You come to this thing expecting that people will make an effort. It can be quite expensive to buy these things, like I know some of the guys in my group went and bought Ralph Laurent pants because they were the only ones that were white and they were like \$200 a pair so they will wear them again but yeah. (Tracey)

Importantly, participants had various domains of practice through which they could express their personal investedness:

If you are a real foodie person you can make it all about the food and if you are a real fashion person you can make it all about the fashion, whatever [is] your thing you can bring it to the event. (Stephanie) 
The examples above represent forms of indirect inducement whereby participants not only made a concerted effort themselves to invest in the vision of the event but also encouraged or even expected fellow attendees to do likewise. However, it is useful to stress two points: firstly, investedness was not consistent across all participants, and there was evidence of 'highly invested champions', who 'bought into' the events' vision, playing significant roles in preparatory behaviours. Secondly, investedness, in the data, was strongly gendered, with women in groups invariably committing more to preparation. For example, an elderly woman reported: "I did a Vitello Tonnata (tuna-based dish), [another woman] would bring the glasses, Eve would bring the candles, Lily brought all the flowers" (Frolinda). Women also reported either purchasing the clothes for their male companions or at least imploring them to do so. Repeated male perspectives suggested that they did "not prepare at all" (Eric), and that "the preparation wasn't the event, it was just preparation" (Jan).

These findings raise important questions regarding the role of key instigators and drivers within networks of participants who were willing and able to mobilise social, cultural, economic and associated temporal resources to invest in constructing these experiences. Such questions, which we revisit in the conclusion, may drive future studies. However, the next section continues to explore investedness and the processes leading participants to enact experiences during the events.

\subsection{Socialised performances}

The fundamental nature of pop-up events makes their success highly reliant on the merging of organisationally governed discourses and consumers' material and embodied performances during the event. Food, drink, cutlery, crockery, drinking vessels and other table accessories became material reifications of the experiential proposition. Moreover, they reflected the values, dispositions and capabilities of those attending, including their desire to enact or 'perform' the meal experience:

Risotto, minced pork, dessert, red wine, white wine, Prosecco, glassware. We put a lot of effort into it, it was perfect. We had different glassware for each course. Also we had white flowers, flower pots. We set the table as we would do it at home, with everything. And obviously, we had to carry all those things. Yes, and it was a good risotto! (Jurg)

As a whole you need to be well presented from the aspect of what the crux of the [White dinner] is all about because it is all about presentation and dressing up and making yourself look important and then the presentation of your table is important because it is a reflection of who you are and what you like and your creativity. (Sophie)

Beyond materiality, the White event experience was intimately tied to performing behaviours. Building on themes from the previous section, the body aesthetic was key:

Well you do expect everyone to dress up nicely so you would want to have that impression of yourself as well rather than turn up at the event like you just climbed out of bed. I would have a judgement of someone else as well if they showed up like that I think. (Chelsea) 
However, the White experience also involved a number of embodied acts expected from participants. Performing specific behaviours reflected participants' cultural capital insofar as they understood the implicit rules and roles of rituals, and the ongoing observance of such practices signalled the willingness to embrace group habitus because it served collective experiential goals.

\section{I can't imagine going there and not doing that. Saying oh why is everyone else waving their napkin, I'm going to sit here and not do it why would you do that? You would be a... don't want to say idiot but a grumble bum ... why would you be at an event like that if you weren't going to participate? (Michael)}

Importantly, the data stressed the ongoing roles of surveillance and peer socialisation in continuing processes of enactment. Performativity played out in the roles of observed and observer. Observation was casual but constant, for example: "It was funny to see who brought what." (Chiara); or "We really enjoyed observing what other people brought to the event. Not just the food in baskets... but also chandeliers, decoration, a lot of fantasy and effort put in." (Jan).

Crucially, surveillance involved judgement and competition: "Obviously, between us women it was about who was wearing what. Did they go out and buy extra stuff, such as umbrellas? Look at them!" (Chiara). Others were very conscious of being watched: "Everyone wants to show off a little bit. Not really like a competition, but a lot of eyeballing" (Sonia). Consequently, anxieties emerged: "Oh, do I look like a painter?" (Sonia).

'Self-policing' within groups, concern towards the conformity of others and appreciation for the event rituals were common sub-themes that indicated a shared responsibility to uphold the event's theme and experiential propositions. For example: "It was important to my parents that it didn't look like cheap plastic cutlery and plates. They brought some decoration, like sea stars, to make it look elegant." (Julia). Self and mutual surveillance, coupled with behavioural co-production, thus reflected acute awareness of the social and cultural risks associated with the failure to adequately interpret and perform the values embedded in the collective event.

\section{Discussion}

Previous research focusing on the processes and agencies involved in experience co-creation contended that organisations may attempt to orchestrate multiple human and material components (Berry, Carbone, \& Haeckel, 2002; Payne, Storbacka, \& Frow, 2008; Zomerdijk, \& Voss, 2010), but propositions were realised through consumer cocreation - involving interpretation, translation and enactment (Lugosi, 2014; Mijnheer, \& Gamble, 2019; Prebensen et al., 2018). Importantly, co-creation takes place in spaces where producers interact directly with consumers (i.e. in virtual and physical servicescapes), alongside consumer spaces outside of the organisations' gaze and governability (Grönroos \& Voima, 2013; Helkkula et al., 2012; Torres et al., 2018).

Moreover, previous research identified and distinguished between spatial, material, embodied performative and representational practices of 'inducement', through which producers and consumers construct experiences (Lugosi, 2014). It is apparent that the outcome of these practices is shaped by complementary and conflicting goals and capacities of stakeholders, including the forms of value they wish to extract 
alongside the skills and resources they can mobilise. The data in this study extend this area of debate by distinguishing between implicitly and explicitly coded practices through which organisations attempt to direct consumer behaviours to enact experiential propositions and realise value in use. This in turn helps to conceptualise direct and indirect forms of inducement as different pathways to achieving experiential outcomes. These pathways are summarised in Figure 1 and discussed in the following paragraphs.

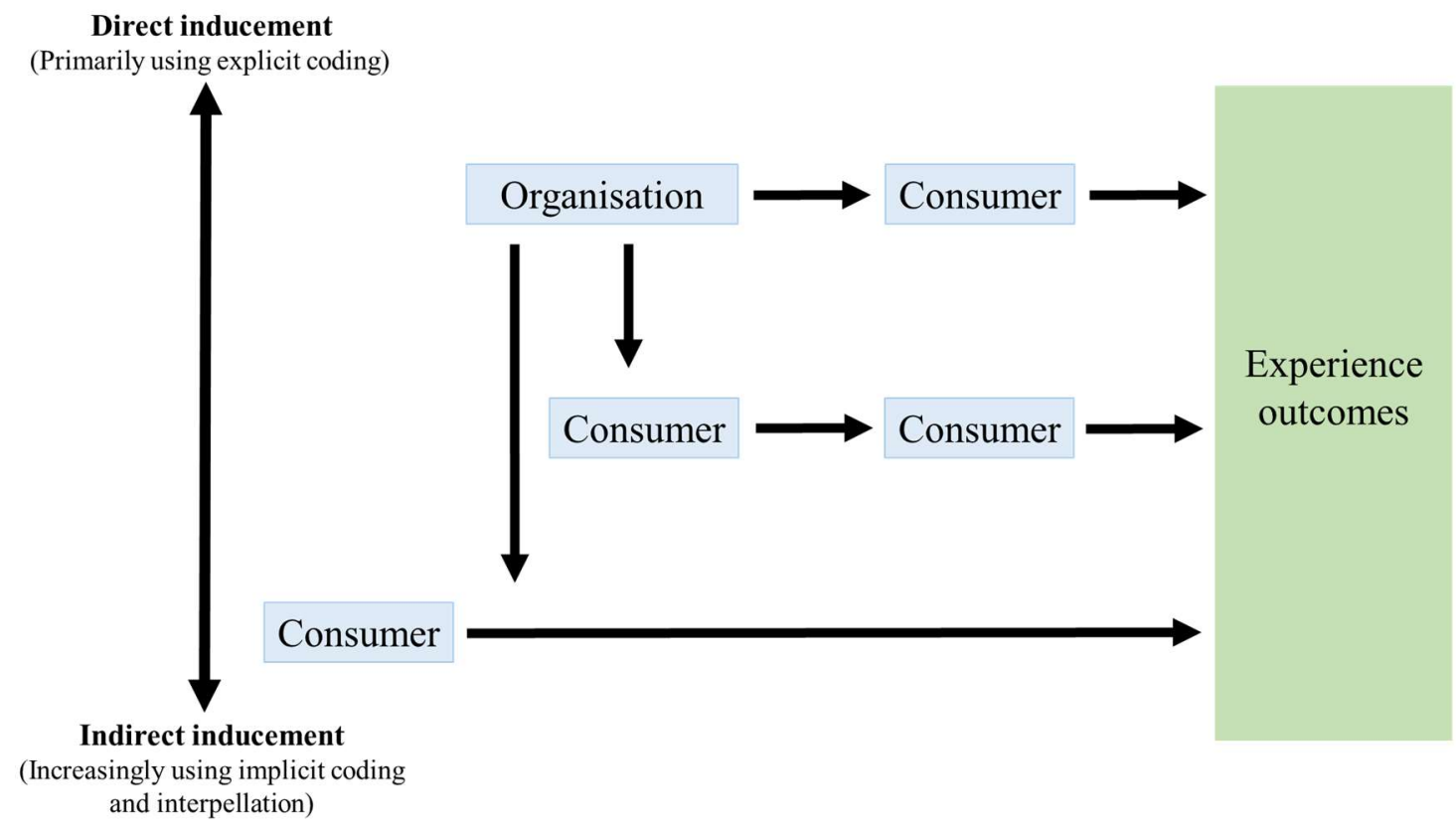

Figure 1. Pathways to experience outcomes

The data highlight how organisations may attempt direct inducement, engaging consumers through explicitly coded instructions and rules, in this case wearing white clothing, creating white decorations and performing specific behaviours such as preparing appropriate food and following prescribed, ritualised elements of the experience (e.g. waving napkins). This affords organisations a certain level of predictability and control over consumer practices and thus their experiential outcomes. However, the mobile nature of pop-up events means that not all the human and material components are predictable or governable in each iteration of the event, especially as participants interpret and customise elements according to their tastes and resources.

As chains of communication and interaction between organisations and consumers extend, information is transmitted and power is projected through social relationships and networks operating in spaces increasingly outside of the sphere of organisations' direct influence (Grönroos \& Voima, 2013; Torres et al., 2018). Consequently, organisations must utilise indirect forms of inducement, requiring consumers to act as proxies in mediating information, socialising others and directing their behaviours. Increasingly important to these practices are what we call 'valuesignalling' - implicitly coded discourses, linked to wider culturally-specific symbolic systems. Value-signalling operates on the principle that multiple forms of value can be created, 'in-use', through the experiences (Sandström et al., 2008), and that organisations cooperate with consumers to conceptualise and communicate the experiential possibilities in their propositions, whilst simultaneously indicating the practices required to realise 'value' (Ballantyne \& Varey, 2006). Value-signalling 
reflects attempts to codify brand identities, images and values by juxtaposing and deploying cultural, aesthetic and moral signifiers (Schroeder, 2009), which are used to mobilise consumers to develop affective bonds that translate into co-creation practices (Pongsakornrungsilp \& Schroeder, 2011).

In the case of White events, the willingness and ability to participate was coupled with, and therefore reliant upon, class-specific skills and capacities - often iteratively induced over time, prior to the event, through non-organisational spaces, or 'consumer spheres' (Grönroos \& Voima, 2013). Value-signalling thus helped co-creation to operate in and across multiple spaces. Investing in clothes, creating dishes and the fundamental desire to engage in these events on these terms required economic and cultural capital (Bourdieu, 1986). Indirect inducement and implicit coding, through value-signalling, thus relies on a system of shared cultural values, with a common index of signs transmitting what is meaningful, desired and thus acceptable (cf. Bakhtin, 1986; Barthes, 1993; Vološinov, 1986). These were mobilised in this event context via appropriating symbolically-laden artefacts (clothing, cutlery, foodstuffs, tableware and other decorations) and assigning values to practices tied to group habitus (e.g. investing in the 'right' clothing, dressing up, attending the events, and performing event-specific rituals) (Bourdieu, 1977). The notions of propriety performed through material and embodied practices were also tied to social and cultural risks, for the event experience, its constituents and individuals, associated with the failure to recognise or adequately conform to group habitus. Ongoing (self and peer) surveillance and self-disciplining to avoid 'deviance labelling' (Adler \& Adler, 2015), reflects the exercise of power within the co-creation process.

Within this pop-up event context, exclusivity and elusiveness were fundamental to the value-signalling of experiential propositions. In such scenarios, organisations have no direct or indirect interactions with consumers, at least in the early stages of relationships. Such organisational strategies make commonly recognised valuation systems and indexes of value even more important in transmitting meanings and expectations surrounding the event, and in mobilising potential consumers to invest in participating. Value-signalling was analogous to Althusser's (2001) notion of 'interpellation' through which individuals became the subjects of event-specific 'cultural utterances' - expressions of encoded class and identity position, referencing ideologies regarding what is valued (Bakhtin, 1986; Vološinov, 1986). Importantly, further reflecting the importance of habitus and forms of capital, consumers had the necessary dispositions and capacities to recognise the communication signals and interpret the meaningfulness of the signs. They identified with the values being communicated, and possessed the resources to invest in event experience co-creation.

Value-signalling, conceptualised in relation to Althusser's (2001) interpellation thus helps to understand the processes of engaging and mobilising consumers in the cocreation process. Moreover, value-signalling was utilised in direct and indirect inducement. The desire for unique, food-based experiences, available to a select group, where participation requires significant economic resources and the adoption of a groupspecific cultural lexicon and performative repertoire is inherently tied to a wider classbased social value system. Within the pop-up event context of White Dinners, recognising and identifying with the values embedded in the experiential proposition also required internalising them insofar as they drove investment and required multiple resources. Specifically, participants identifying with and therefore desiring the experiential propositions had to learn (in this case about the event, and the terms of 
engagement), and access resources necessary for participation (i.e. economic and cultural capital required to buy clothing, specialist objects, selecting and preparing food, alongside social capital as they mobilised others).

\section{Conclusion}

This paper has sought to conceptualise how organisations attempt to manage cocreation practices. It responds to assertions that the co-creation literature tends to be atheoretical (Duerden et al., 2018) and in need of "propositions or strategies for managing or facilitating co-creation" (Ellis et al., 2019, p.113). The paper focused on pop-up food tourism events as its empirical context for examining these issues. These arguably act as extreme cases of co-creation dynamics characterised by high levels of irregularity, largely stemming from the spatial variability of the events taking place in diverse venues not originally designed to host them. Nevertheless, the fundamental challenges associated with co-creation emerge in other experiential and service settings, particularly in hospitality, leisure, tourism and events practices (Grönroos \& Voima, 2013; Torres et al., 2018).

The paper distinguished between direct and indirect pathways, identifying how implicit and explicitly coded practices, and symbolic value systems may be used by organisations to induce, or engage and mobilise, their stakeholders. Specifically, the data helped to conceptualise how organisations may utilise value-signalling in their attempts to communicate the experiential propositions of their services and events; and, importantly, how they seek to instigate specific practices among consumers through which value within those propositions were realised and enacted. Much of the existing work on experience management and co-creation has focused on the joint spaces where organisations and consumers directly interact, and on managing the consumer journey within the servicescape (cf. Berry et al., 2002, 2006; Grönroos \& Voima, 2013; Hoffman $\&$ Turley, 2002). This paper thus extends current work on co-creation in experiential consumption settings by conceptualising how the strategic use of cultural-specific symbolic systems of meaning and indexes of value, within 'consumer spheres' of practice outside the direct influence of organisations, are used to engage consumers, inducing them to engage in behaviours and mobilise resources to create experiential value.

\subsection{Managerial implications}

There are inherent risks in assuming that organisations can 'manage' consumer behaviour through prescriptive strategies such as service blueprinting and scripting alone. These tactics inevitably have important applications but are less effective in service and consumption settings characterised by high levels of variability. Moreover, they do not help to understand or manage co-creation outside of the spaces where organisations and consumers directly interact. It is therefore necessary to appreciate, firstly, the broader composition of (intangible) values entangled in experiential propositions, and secondly, the practices required among consumers (and providers) to enact them - making them tangible. This requires marketers, event designers and operators to examine how symbolic value systems can be utilised. In this study, discourses of exclusivity, elusiveness, novelty and variability, aesthetic production and consumption, reflected in clothing, material objects and foodstuffs were used both to position the 'product' in the marketplace, and to engage consumers' co-creation. The challenge is to identify analogous features of service experiences in other contexts. 


\subsection{Theoretical implications}

Based on the themes identified in the data, the discussion drew on the work of political and linguistic theorists, specifically Althusser, Bakhtin and Vološinov, to interpret the processes through which consumers are 'interpellated': becoming subjects, and agents, of organisational discourses. It was argued that mobilising an ordered web of signs, tied to a culturally (in this case class-) specific web of meanings, can be conceived as a series of 'utterances' which shaped the terms of engagement and practices of co-creation among consumers. Consumers' desire and ability to engage in specific co-creation practices was shaped by the ways in which they recognised, internalised, adapted and responded to those utterances. This conceptualisation of the processes used by organisations and consumers to 'hail' individuals and shape their cocreation offers ways to understand how and why consumers engage, invest and perform specific behaviours in other consumption contexts, especially those characterised by exclusivity, elusiveness and ambiguity.

\subsection{Limitations and areas for further research}

This study focused on a specific experiential setting as the empirical context, examining consumers' perspectives in two countries, drawing on one type of qualitative data. It is also important to acknowledge the class dimensions of this experiential context and the sample. Starting with the later, although we did not collect information regarding income or occupation, it is necessary to acknowledge that the White events, and therefore our sample of people who attend them, reflect 'middle' or 'higher' class dispositions and capacities. This may be seen as a limitation of our study and the transferability of the findings, stemming from a sampling bias. Value-signalling, inducement and the mobilisation of consumers' embodied co-creation in this context thus drew on values and practices relevant to people assuming specific class positions or statuses (e.g. concerning gastronomic repertoires, hedonistic consumption, brandtribe affiliation, exclusivity etc.). Subsequent studies can examine how value-signalling and inducement operate in radically different experiential settings, targeting consumers identifying with alternative class habitus.

Future research can thus consider how interpellation operates in other consumption contexts. This could include White or other pop-up food events in alternative national or cultural settings, but may extend to other forms of experiential consumption, particularly those characterised by strong boundary maintenance and exclusion that require significant investment from consumers to participate. This could draw on other forms of qualitative material, for example netnographic data regarding activities in virtual settings, that also adopt practices of interpellation, utilising symbolic values and principles in creating experiential propositions and driving co-creation.

This study also highlighted the role of key individuals within networks of consumers who invest more intensely through their own economic, cultural and social resources. Future research may focus more specifically on the psychological and social characteristics of these individuals and how these characteristics shape co-creation within experiential settings. Examining how actors 'colonise' foodie spaces and places that derive social capital (cf. Robinson, Getz \& Dolnicar, 2018) could also enhance our understanding of the pop-up event phenomena. Linked to the previous point, the data in this study highlighted the gendered nature of co-creation. Future studies can thus examine how gender identities may influence the scope and forms of co-creation. 


\section{References}

Aaltojärvi, I., Kontukoski, M., \& Hopia, A. (2018). Framing the local food experience: A case study of a Finnish pop-up restaurant. British Food Journal, 120(1), 133145.

Adams, M. (2006). Hybridizing habitus and reflexivity: Towards an understanding of contemporary identity?. Sociology, 40(3), 511-528.

Adler, P.A., \& Adler, P. (2015). Constructions of deviance: Social power, context, and interaction (8th ed.). Belmont, CA: Wadsworth.

Althusser, L. (2001[1971]). Lenin and philosophy and other essays. Trans. Brewster, B. New York: Monthly Review Press.

Ballantyne, D., \& Varey, R. J. (2006). Creating value-in-use through marketing interaction: the exchange logic of relating, communicating and knowing. Marketing Theory, 6(3), 335-348.

Bakhtin, M.M. (1986[1953]) Speech genres and other late essays. Trans McGee, V. W. Austin: University of Texas Press.

Barthes, R. (1993[1957]). Mythologies. Trans. Lavers, A. London: Vintage.

Batat, W., Peter, P.C., Moscato, E.M., Castro, I.A., Chan, S., Chugani, S., \& Muldrow, A. (2019). The experiential pleasure of food: A savoring journey to food wellbeing. Journal of Business Research, 100, 392-399.

Bell, D. (2007). The hospitable city: Social relations in commercial spaces. Progress in Human Geography, 31(1), 7-22.

Berridge, G. (2007). Events design and experience. Oxford: Elsevier.

Berry, L.L., Carbone, L. P., \& Haeckel, S.H. (2002). Managing the total customer experience. MIT Sloan Management Review, 43(3), 85-89.

Berry, L.L., Wall, E.A., \& Carbone, L.P. (2006). Service clues and customer assessment of the service experience: Lessons from marketing. Academy of Management Perspectives, 20(2), 43-57.

Bitner, M.J., Ostrom, A., \& Morgan, F. (2008). Service blueprinting: A practical technique for service innovation. California Management Review, 50(3), 66-94.

Bourdieu, P. (1977[1972]). Outline of a theory of practice. Trans. Nice, R. Cambridge: Cambridge University Press.

Bourdieu, P. (1984[1979]). Distinction: A social critique of the judgement of taste. Trans. Nice, R. London: Routledge.

Bourdieu, P. (1986). Forms of capital. In J.G. Richardson (Ed)., Handbook of theory for the sociology of education (pp. 241-258). New York, NY: Greenwood Press.

Bowdin, G., Allen, J., O'Toole, W., Harris, R., \& McDonnell, I. (2012). Events management (3rd ed.). Abingdon: Routledge.

Braun, V., \& Clarke, V. (2006). Using thematic analysis in psychology. Qualitative Research in Psychology, 3, 77-101.

Binkhorst, E., \& Den Dekker, T. (2009). Agenda for co-creation tourism experience research. Journal of Hospitality Marketing and Management, 18(2-3), 311-327.

Cannas, R., Argiolas, G., \& Cabiddu, F. (2019). Fostering corporate sustainability in tourism management through social values within collective value co-creation processes. Journal of Sustainable Tourism, 27(1), 139-155.

Crowther, P., \& Donlan, L. (2011). Value-creation space: The role of events in a servicedominant marketing paradigm. Journal of Marketing Management, 27(13-14), 1444-1463. 
De Lassus, C., \& Freire, N.A. (2014). Access to the luxury brand myth in pop-up stores: A netnographic and semiotic analysis. Journal of Retailing and Consumer Services, 21(1), 61-68.

Denzin, N. (2009). The research act. New Brunswick, NJ: Aldine Transaction.

Duerden, M.D., Ward, P.J., \& Freeman, P.A. (2015). Conceptualizing structured experiences: Seeking interdisciplinary integration. Journal of Leisure Research, 47(5), 601-620.

Duerden, M.D., Lundberg, N.R., Ward, P., Taniguchi, S.T., Hill, B., Widmer, M.A., \& Zabriskie, R. (2018). From ordinary to extraordinary: A framework of experience types. Journal of Leisure Research, 49(3-5), 196-216.

Ellis, G.D., Freeman, P.A., Jamal, T., \& Jiang, J. (2019). A theory of structured experience. Annals of Leisure Research, 22(1), 97-118.

Ferreri, M. (2015). The seductions of temporary urbanism. ephemera, 15(1), 181-191.

Grönroos, C., \& Voima, P. (2013). Critical service logic: Making sense of value creation and co-creation. Journal of the Academy of Marketing Science, 41(2), 133-150.

Hammersley, M. (2010). Methodology: Who needs it?. London: Sage.

Harris, E. (2015). Navigating pop-up geographies: Urban space-times of flexibility, interstitiality and immersion. Geography Compass, 9(11), 592-603.

Harris, E. (2017). Reimagining space-time in the contemporary city. Unpublished $\mathrm{PhD}$ Thesis, Royal Holloway, University of London.

Helkkula, A., Kelleher, C., \& Pihlström, M. (2012). Characterizing value as an experience: Implications for service researchers and managers. Journal of Service Research, 15(1), 59-75.

Hietanen, J., Mattila, P., Schouten, J.W., Sihvonen, A., \& Toyoki, S. (2016). Reimagining society through retail practice. Journal of Retailing, 92(4), 411425.

Holst-Kjaer, S. (2011). Meaningful experience creation and event management: A postevent analysis of Copenhagen carnival 2009. Culture Unbound: Journal of Current Cultural Research, 3, 243-267.

Hoffman, K., \& Turley, L. (2002). Atmospherics, service encounters and consumer decision making: An integrative perspective. Journal of Marketing Theory and Practice, 10(3), 33-47.

Hoffman, S. (2015). The rise of pop-up dining events and the experiential diner. http://www.eventbrite.com/ (Accessed, 03.03.16).

Jaakkola, E., Helkkula, A., \& Aarikka-Stenroos, L. (2015). Service experience cocreation: Conceptualization, implications, and future research directions. Journal of Service Management, 26(2), 182-205.

Jones, P., Comfort, D., \& Hillier, D. (2017). A Commentary on Pop up Hospitality Ventures in the UK. Athens Journal of Tourism, 4(3), 203-216.

Kim, H., Fiore, A.M., Niehm, L.S., \& Jeong, M. (2010). Psychographic characteristics affecting behavioral intentions towards pop-up retail. International Journal of Retail and Distribution Management, 38(2), 133-154.

Klein, J.F., Falk, T., Esch, F.R., \& Gloukhovtsev, A. (2016). Linking pop-up brand stores to brand experience and word of mouth: The case of luxury retail. Journal of Business Research, 69(12), 5761-5767.

Laing, J. (2018). Festival and event tourism research: Current and future perspectives. Tourism Management Perspectives, 25, 165-168. 
Lim, C.J. (2015). Agents for urban food education and security. Architectural Design, 85(3), 92-99.

Lincoln, Y.S., \& Guba, E.G. (2013). The constructivist credo. London: Left Coast Press.

Lugosi, P. (2014). Mobilising identity and culture in experience co-creation and venue operation. Tourism Management, 40, 165-179.

Lugosi, P. (2019). Deviance, deviant behaviour and hospitality management: Sources, forms and drivers. Tourism Management, 74, 81-98.

Lugosi, P., Bell, D., \& Lugosi, K. (2010). Hospitality, culture and regeneration: Urban decay, entrepreneurship and the 'ruin' bars of Budapest. Urban Studies, 47(14), 3079-3101.

Lugosi, P., Robinson, R. N., Golubovskaya, M., Foley, L., \& Harwell, J. (2016). Experiencing parenthood, care and spaces of hospitality. The Sociological Review, 64(2), 274-293.

Lundberg, C., \& Ziakas, V. (2018). Fantrepreneurs in the sharing economy: Cocreating neotribal events. Event Management, 22(2), 287-301.

Marques, L., \& Borba, C. (2017). Co-creating the city: Digital technology and creative tourism. Tourism Management Perspectives, 24, 86-93.

McLaren, D., \& Agyeman, J. (2015). Sharing cities: A case for truly smart and sustainable cities. Cambridge: MIT Press.

Mijnheer, C.L., \& Gamble, J.R. (2019). Value co-creation at heritage visitor attractions: A case study of Gladstone's Land. Tourism Management Perspectives, 32, 100567.

Morgan, M. (2008). What makes a good festival? Understanding the event experience. Event Management, 12(2), 81-93.

Obrador Pons, P. (2020). A freegan pop-up café: Embedding critical hospitalities into the curriculum. Hospitality and Society, 10(1), 87-106.

Özdemir, B., \& Seyitoğlu, F. (2017). A conceptual study of gastronomical quests of tourists: Authenticity or safety and comfort?. Tourism Management Perspectives, 23, 1-7.

Patton, M.Q. (2014). Qualitative research and evaluation methods (4th edn). London: Sage.

Payne, A.F., Storbacka, K., \& Frow, P. (2008). Managing the co-creation of value. Journal of the Academy of Marketing Science, 36(1), 83-96.

Plester, B. (2015). Ingesting the organization: The embodiment of organizational food rituals. Culture and Organization, 21(3), 251-268.

Pongsakornrungsilp, S., \& Schroeder, J.E. (2011). Understanding value co-creation in a co-consuming brand community. Marketing Theory, 11(3), 303-324.

Ponsignon, F., Durrieu, F., \& Bouzdine-Chameeva, T. (2017). Customer experience design: A case study in the cultural sector. Journal of Service Management, 28(4), 763-787.

Prebensen, N.K., Chen, J.S., \& Uysal, M. (Eds.). (2018). Creating experience value in tourism (2nd ed.).Wallingford: CABI.

Prebensen, N. \& Xie, J. (2017). Efficacy of co-creation and mastering on perceived value and satisfaction in tourists' consumption. Tourism Management, 60, 166176.

Putnam, R.D. (2000). Bowling alone: The collapse and revival of American community. New York, NY: Simon and Schuster. 
Robinson, R.N.S., Getz, D., \& Dolnicar, S. (2018). Food tourism subsegments: A datadriven analysis. International Journal of Tourism Research, 20(3), 367-377.

Sandström, S., Edvardsson, B., Kristensson, P., \& Magnusson, P. (2008). Value in use through service experience. Managing Service Quality, 18(2), 112-126.

Scott, N., Gao, J., \& Ma, J. (Eds.). (2017). Visitor experience design. Wallingford: CABI.

Schaller, S., \& Guinand, S. (2018). Pop-up landscapes: a new trigger to push up land value? Urban Geography, 39(1), 54-74.

Schroeder, J.E. (2009). The cultural codes of branding. Marketing Theory, 9(1), 123126.

Schwandt, T.A. (1996). Farewell to criteriology. Qualitative inquiry, 2(1), 58-72.

Shields, R. (1991). Places on the margin: Alternative geographies of modernity. London: Routledge.

Sterchele, D. (2020). Memorable tourism experiences and their consequences: An interaction ritual (IR) theory approach. Annals of Tourism Research, 81, 102847.

Taylor, S., DiPietro, R.B., \& So, K.K.F. (2018). Increasing experiential value and relationship quality: An investigation of pop-up dining experiences. International Journal of Hospitality Management, 74, 45-56.

Torres, E.N., Lugosi, P., Orlowski, M., \& Ronzoni, G. (2018). Consumer-led experience customization: a socio-spatial approach. Journal of Service Management, 29(2), 206-229.

Tum, J., Norton, P., \& Wright, J.N. (2006). Management of event operations. Oxford: Elsevier.

Vološinov, V.N. (1986[1929]). Marxism and the philosophy of language. Trans. Matejka, L., \& Titunik, I.R.. London: Harvard University Press

Warde, A. (2016). The practice of eating. Cambridge: Polity Press.

Werner, K., Griese, K.M., \& Faatz, A. (2019). Value co-creation processes at sustainable music festivals: a grounded theory approach. International Journal of Event and Festival Management, 11(1), 127-144.

Ziakas, V., \& Costa, C.A. (2012). 'The show must go on': Event dramaturgy as consolidation of community. Journal of Policy Research in Tourism, Leisure and Events, 4(1), 28-47.

Ziakas, V., \& Boukas, N. (2013). Extracting meanings of event tourist experiences: A phenomenological exploration of Limassol carnival. Journal of Destination Marketing and Management, 2(2), 94-107.

Zomerdijk, L.G., \& Voss, C.A. (2010). Service design for experience-centric services. Journal of Service Research, 13(1), 67-82. 


\section{Appendix 1. Core interview questions and indicative follow-up probes}

\section{What do you know about Diner en Blanc?}

-How many Diner en Blanc events have you been to?

-Where have they been located?

-How did you initially hear about the event?

-Have you been to any similar events like this before?

\section{How far in advance would you prepare for Diner en Blanc?}

-What do you prepare first, outfit, food, table setting?

-What do you like about preparing for Diner en Blanc?

-How important it is to you to be well prepared/presented?

-Do you decide all of these elements on your own or with your partner/group?

\section{Have you made friends/connections through attending Diner en Blanc?}

-Who do you take with you to Diner en Blanc? Further probe: Why?

-Do you still keep in contact with these people?

-What did you do at the event? Further probe: Did you predominately stay at your table, walk around or go to the dancefloor?

-How do you feel about sharing a table with a big group of people?

-What sort of things did you talk about at your table?

-Would you recommended this event to a friend? Further probe: Have you done so in the past?

4. Tell me about the items you bring along to Diner en Blanc.

-What would your typical table look like/what did your table feature?

-Why did you choose these brands of food, crockery, etc.?

-Do you like to go for a particular theme?

-Why did you bring these things over others?

-Are you/have you been interested or involved in any of the competitions that the event offers (e.g. Best Table Decorations, Best Dressed etc.)?

5. Tell me what you think about the location of Diner en Blanc events.

-Do you like the element of surprise?

-How did you feel when you found out the secret location? Further probe: Did this change throughout the night?

-Have you been particularly impressed by a space that has been transformed by Diner en Blanc? Further probe: If so where and why?

-Does this event take you out of your comfort zone? Further probe: If so, in what way?

6. Tell me what you think about the Diner en Blanc guidelines/rules.

-Have you had any positive or negative experiences with them? Further probe: Do you have an example you could share?

-Do you feel like these rules restrict you at all?

-Do the rules impact you on the event night or purely in the lead up/preparation phase?

-If applicable: Have your thoughts/feelings about the rules changed from your first time to your second time attending? 
7. Diner en Blanc has been labelled a pop-up event, one that seemingly 'pops up' and then disappears with no trace. Do you think Diner en Blanc is a successful pop-up event?

-What is your understanding of a pop-up event?

-Have you been to many pop-up events before?

-Why do you think Diner en Blanc is (un)successful as a pop-up event?

8. Tell me about your perceptions of the atmosphere at a Diner en Blanc event. -How do you feel about the crowding?

-Do you enjoy the table layout, men on one side, women on the other?

-Do you enjoy using the dancefloor?

-What kind of lighting do you opt for?

9. Do you feel like you would spend more or less than the average person on Diner en Blanc?

-Why is this so?

-What type of items do you feel are worth spending money on for Diner en Blanc?

-What do a large portion of your funds go towards when participating in this event?

10. Why have you chosen to participate in Diner en Blanc in the past?

-What attracted you to a pop-up dinner rather than going to a restaurant?

-How far would you be willing to travel for an event like this? 